\title{
Study and Development Trend of the Cigarette Market in the Republic of Armenia
}

\author{
A.H. Parsyan \\ Armenian National Agrarian University
}

S.H. Parsyan

Hrayr Maroukhian Foundation

annaparsyan85@mail.ru, surenparsyan@gmail.com

\section{A R T I C L E IN F O}

Keywords:

cigarette,

production,

entrepreneurial activity,

export,

import,

market

\begin{abstract}
A B S T RA C T
The article discusses tobacco cultivation and cigarette production sector as a traditional and developing branch of the RA economy. The entrepreneurial activities of cigarette producing organizations in the RA have been introduced and emphasized.

The production and export indices of cigarette manufacturing companies have been studied, the exported and imported ratios of cigarettes have been collated and increasing - declining trends have been determined. Besides, cigarette market capacity and self-sufficiency rate has been estimated through specific methodology.
\end{abstract}

\section{Introduction}

In Armenia the entrepreneurship in cigarette production has been developed since the post-Soviet years. Per the data of 2020, five companies are already engaged in the mentioned sector: "Grand Tobacco" LLC, "International Masis Tabak" LLC, "Masis Tobacco" LLC, "SPS Cigaronne" LLC and "Armenian Tobacco Company" LLC. Identification of the issues related to the entrepreneurial activities of cigarette and cigar manufacturing companies of the RA is rather relevant for the economy of Armenia. According to the official data, in the last five years, cigarette is the second most exported product from Armenia. The specific weight of tobacco products manufacture in the overall industrial products of the RA amounted from $2 \%$ (2010) up to $9.4 \%$ (2020). The need for the development of this branch is enhanced upon the availability of land and labor resources. By providing the branch companies with domestic raw materials and reducing the dependence on the imported raw materials, hence, avoiding the fluctuations in international exchange rates, not only the economic, but also one of the most important social issues in the RA, i.e., reduction of unemployability rate, will be handled. That is, an opportunity can be created to provide, for instance, the residents of border regions with appropriate jobs. 


\section{Materials and methods}

Cigarette and cigar production is a traditional and fast growng subbranch of Armenian economy provided with both domestic and imported raw material (Parsyan, 2021). All companies engaged in entrepreneurial activities in the cigarette and cigar production sector are involved in the list of 1000 large tax payers annually published by the State Revenue Committee of the RA. According to the data provided by the SRC, in 2016, 2017 and 2018 "Grand Tobacco" LLC was in the second position among the tax payers, being the second only to "Gazprom Armenia" in 2016-2017 and to "Zangezur Copper-Molybdenum Combine" in 2018. In 2019-2020, "Grand Tobacco" LLC again topped the list of the RA tax payers (petekamutner. am, 22.10.21). The overwhelming share of cigarette manufacturing companies in the total specific weight of the tax revenues and duties accreted in the RA state budget is related to the growing volumes of the mentioned production and to the amount of income taxes paid from the salaries of great number of employees, as well as to the current high rates of added value and excise taxes (Parsyan, 2017\#3). In 2016-2020, the share of tax receipts entered the RA state budget from the companies engaged in the entrepreneurial activities of cigarette production in the RA tobacco market grew up from $3.1 \%$ to $6.5 \%$.

Thus, the sizes of tax and duties paid to the state budget by the cigarette and cigar manufacturing companies are sustainably growing, which directly promotes the provision of efficiency increase in fiscal policy.

The development tendencies of cigarette and cigar products manufacture, their import and export ratios have been investigated and the market capacity, as well as selfsufficiency rate has been estimated through the method introduced in "Food Security and Poverty" bulletin (Statistical Bulletin, Yerevan-2019).
Market capacity $=$ Production + Import-Export .

Self-sufficiency rate $=\frac{\text { Production }}{\text { Production }+ \text { Import-Export }} \times 100 \%$.

\section{Results and discussions}

Cigarette production sector has been one of the dynamically developing branches of the industry in the Republic of Armenia for the last 20 years. Moreover, up to 2020, before the prevalence of the coronavirus pandemic Covid-19, the cigarette exporting volumes had been annually growing, so becoming one of the sustainable sources for foreign currency flow into Armenia.

In 2020, the cigarette production rate in Armenia, in physical terms, decreased by $17.8 \%$ against the previous year. As of January-August, 2021, the cigarette production volumes were reduced by $16.8 \%$ as compared to the same period of 2020. The data investigation indicates that cigarette production sizes demonstrate decreasing tendency. It is noteworthy, that a considerable decline in the cigarette production volumes was observed still from March, 2020, when the pandemic started spreading in Armenia very rapidly and causing huge damages to almost all economic branches. As a result, according to the data retrieved in 2020, the physical volumes of cigarette production were reduced by $16.8 \%$ falling down to the level recorded in 2017.

It is also worth mentioning, that the specific weight of cigarette manufacture in the overall structure of the RA processing industry has recorded an increasing tendency in the recent years. For example, if in 2011 it made $2.5 \%$, then in 2019 it amounted to $13.4 \%$, while in 2020 - $11 \%$. The indices for 2011-2021 published by the National Statistic Committee are introduced in Figure 1.

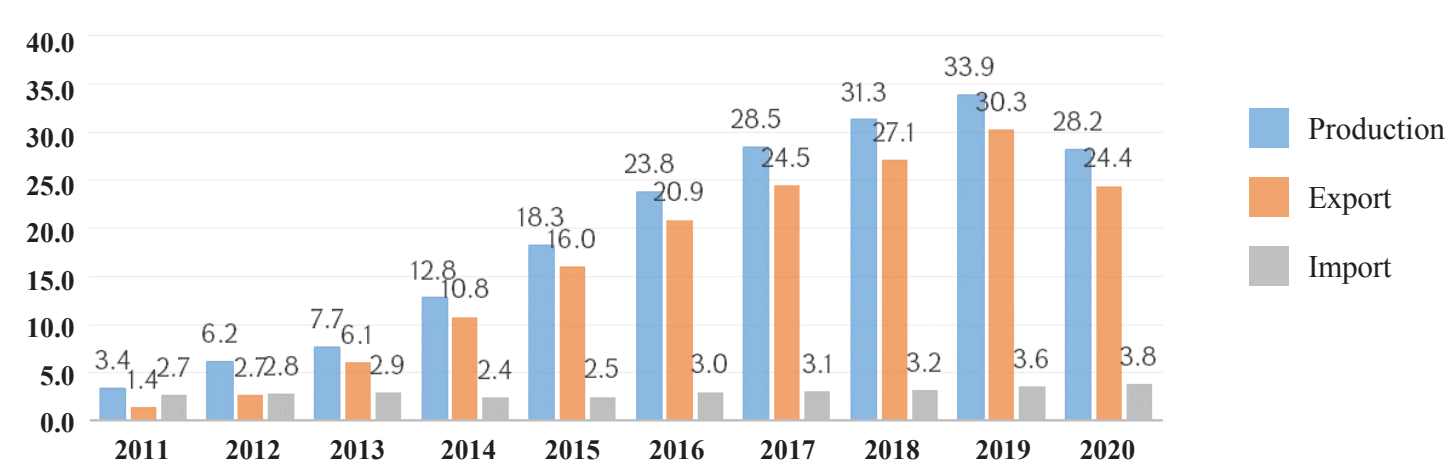

Figure 1. Cigarette production, export and import sizes in the RA within the period of 2011-2020, bln n (Statistical Bulletin, armstat. am 22.10.21) (composed by the authors). 


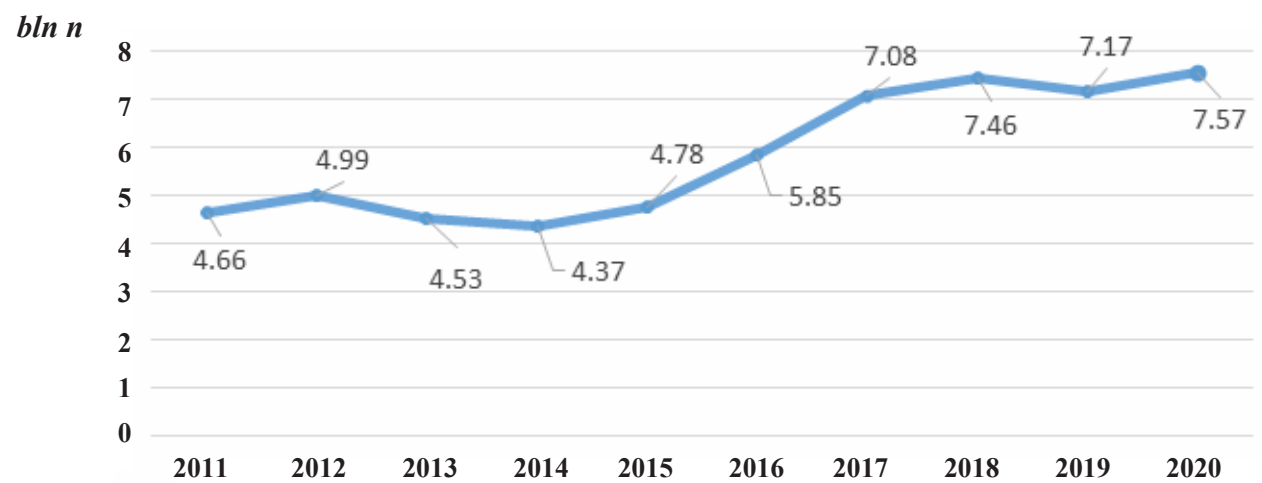

Figure 2. The cigar and cigarette market capacity in 2010-2020 in RA (composed by the authors).

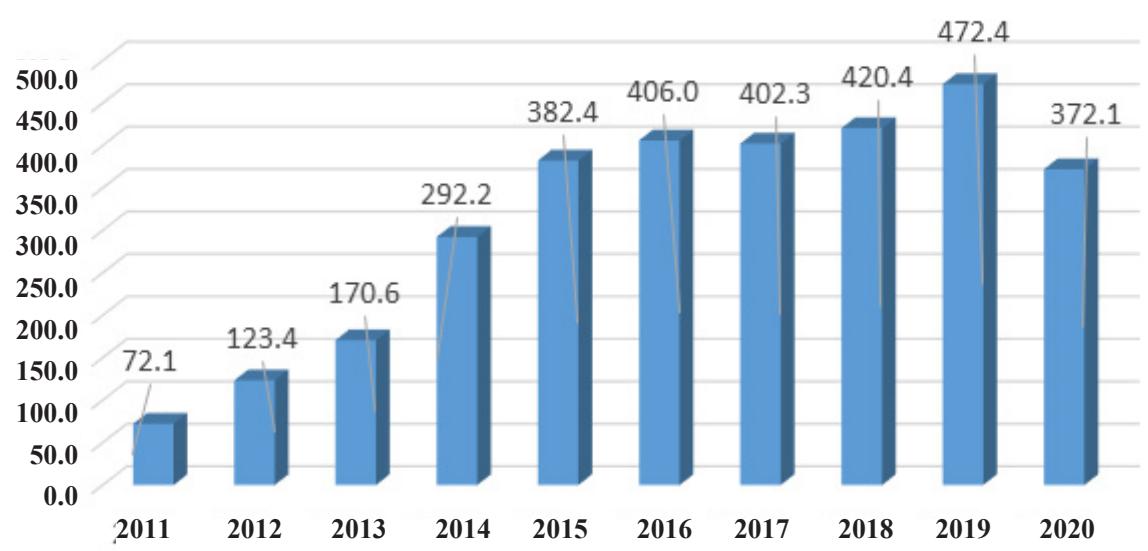

Figure 3. Self-sufficiency rate of cigarette market in 2011-2020, \% (composed by the authors).

In 2011-2020, parallel to the increase of cigarette production sizes, its export volumes grew up. About $83-88 \%$ of the produced cigarettes is annually exported from Armenia. In 2020, 24.4 bln $\mathrm{n}$ cigarettes were exported from Armenia, the total customs cost of which made $241.1 \mathrm{mln}$ US dollars. Compared to 2019, the export volumes decreased by 3.8 bln $n$ or by $13.5 \%$, while the cost - by $32 \mathrm{mln}$ US dollars or by $11.7 \%$.

Despite the reduction of the mentioned indices, cigarette is still in the list of the products with highest exported customs value from Armenia. Particularly, in 2019, it constituted $10 \%$ of exported products in Armenia and in 2020 it made $9.5 \%$. Already in the first half of 2021, cigarettes with the estimated cost of about $101.0 \mathrm{mln}$ US dollars were exported from Armenia, which, compared to the same period of the previous year, is reduced by about $10 \mathrm{mln}$ US dollars or by $8.7 \%$. Armenian cigarettes are mostly exported to Iraq, Syria, UAE, as well as to Georgia, Russia, Ukraine and other countries. Iraq accounts for about $61 \%$ of the exported cigarettes in 2020, Syria - for $16 \%$, UAE - for $12 \%$, etc.

The significance of the specific industrial branch in the national economic system of the country is also based on the identification of the countries, where the sale of the branch product is implemented, or those with which partneship relations are created in order to supply the branch with raw materials and other facilities. For example, the economic entities, engaged in the entrepreneurial activities in the territory of Armenia, purchase raw materials and accessories for cigarette production from such partner countries as Iran, Greece, Bulgaria, Brazil, Republic of South Africa (RSA), Austria, France, Italy, Indonesia, Russian Federation and Turkey.

It is remarkable that the raw products and other supplies required for cigar and cigarette manufacture is mainly purchased by the local companies from abroad. Some accessories for cigarette production are produced just by local companies not to be dependent on foreign market. 
If the production of Virginia, Burley and Samsun tobacco varieties grown in different regions of the RA is able to meet about $15 \%$ of the raw product demand in cigarette manufacturing companies, then the mentioned economic entities face serios problems in acquiring other types of raw products.

The import sizes of cigarettes demonstrate sustainable growth for the period of 2011-2020: in 2020, the imported volume increased in 1.4 times, and the export volume - in 17.4 times against the same indices recorded for 2011. In 2011-2020, the cigarette market capacity in Armenia increased by $62.4 \%$ (Figure 2). Though in 2020 , the cigarette manufacture volume was reduced from 30.3 bln $n$ to 28.17 bln $n$, one of the reasons of the growth in the cigarette market capacity in the RA was the increase in cigarette import volumes.

The self-sufficiency rate of cigarette market annually increased within the period of 2011-2020 due to the increase of cigarette production volumes in the country and their sustainable import sizes. The highest self-sufficiency rate was recorded in 2019, nevertheless, the index of 2020 already demonstrated a decreasing tendency. At the same time, it is worth mentioning, that the overwhelming part of cigarettes produced in the RA for recent years is being exported.

\section{Conclusion}

Tobacco cultivation in the RA has a rather long history. Armenian cigarettes are in great demand both in internal market and in dozens of foreign countries of the world. They are distinguished by high qualitative properties (color, strength). The cigar and cigarette manufacturing organizations of the RA have a number of achievements in their entrepreneurial activities. For dozens of years the cigar and cigarette production sector had been one of the dynamically developing branches in the processing industry of Armenia, anyhow, in 2020 the mentioned sector recorded a decline in the production and economic indices. This tendency was related to the unstable economic situation, rising prices, reduction of population's purchase power, pandemic and war conditions.

Though cigarette is not considered a staple product, its specific weight /share should not be ignored in the overall structure of household expenditures. During 2004-2019, according to the data of statistical-analytical report "Social Snapshot and Poverty in Armenia", the monthly average share of cigarette in the structure of nominal household consumption expenditure made 808-1653 AMD per capita of household (statistical-analytical report, Yerevan, 2018). That is the increase in cigarette prices in the RA has a direct causal effect on the budget expenditure items of entire population and individual households.

Despite the circumstance that the production capacity of tobacco varieties (Virginia, Burley and Samsun) as a cigarette raw material is rather high in Armenia, in 2016-2020 the cigarette and cigar manufacturing companies purchased the cigarette raw products from abroad. Here the companies have to deal with high production, financial and commercial risks.

So, investigating the indices of cigarette production, its export and import volumes, as well as the market capacity and self-sufficiency rate within the period of 2011-2020, it has been found out that the mentioned indices demonstrated a sustainably growing trend. Some variations towards the decreasing trend were related to the pandemic and war conditions. It can be stated that in 2011-2020, the cigarette manufacturing companies were actively engaged in entrepreneurial activities both in Armenia and abroad. Tobacco growing and cigarette manufacturing sector is a sustainably developing branch for Armenia and it is not only of economic but also of social significance providing thousands of work positions.

\section{References}

1. https://www.petekamutner.am/Content.aspx?itn=tsTILists (accessed on 22.10.21).

2. Parsyan, A.H. (2021). Issues of Entrepreneurship Development in the Companies Engaged in the Sector of Cigarette and Cigar Manufacture, PhD Thesis, ANAU, Y.00.02, Yerevan, - 36 p.

3. Parsyan, A. H. (2017\#3). Taxes and Fees Paid by Cigarette and Cigar Producing Companies in RA // Alternative, Scientific Articles , - pp. 108-113.

4. Social Snapshot and Poverty in Armenia, Statistical and Analytical Report, Yerevan 2018, -134 p.

5. Statistical Bulletin. The Main Indicators of Industrial Organizations according to Two-Digit Classification of Economic Activities per Armenian Regions and the City of Yerevan, Yerevan 2020: https://www.armstat. am (accessed on 22.10.21).

The research was carried out with the financial support of the Russian Foundation for Basic Research and the Science Committee of the $R A$ within the framework of the scientific project No. 20-510-05020 20 (No. 20RF-054). 